\title{
Preliminary Design of Advanced Flight Control System Architectures for Commercial Transport Aircraft
}

\author{
Thomas Lampl \\ Institute of Aircraft Design, Technical University of Munich \\ Research Associate \\ Boltzmannstraße 15, 85748 Garching, Germany \\ lampl@tum.de \\ Timo Wolf \\ Institute of Aircraft Design, Technical University of Munich \\ Graduate Student \\ Mirko Hornung \\ Institute of Aircraft Design, Technical University of Munich \\ Professor, Head of Institute
}

\begin{abstract}
The functional enhancement of Flight Control Systems (FCS) show potential benefits for commercial transport aircraft. Furthermore, the consideration of new technologies and more-electric concepts lead to a significant increase of the design space for FCS architectures. The objective of this contribution is to enable the preliminary design of advanced FCS architectures for a given FCS configuration. Based on a comprehensive literature research, the main subsystems are identified and simplified models of the architecture are developed. Additionally, technological constraints as well as design rules for actuator distribution, and power redundancy are defined. The design rules for advanced FCS architectures are derived from the basic design rules of existing FCS architectures of commercial transport aircraft. Finally, the presented method is implemented into a design tool. The resulting tool enables the preliminary design of multifunctional FCS architectures.
\end{abstract}

KEYWORDS: flight control system architecture, high-lift control system, flight control computer, actuator, power supply

\section{INTRODUCTION}

The Flight Control Systems (FCSs) of today's commercial transport aircraft are full fly-by-wire systems with very stringent requirements in terms of safety ${ }^{1}$, availability and reliability [1]. Furthermore, it is one of few aircraft systems with strong physical and information based integration. Recent FCS of commercial transport aircraft consist of highly optimized and mainly mono-functional flight control devices. This knowledge-based FCS design is often limited to small and local improvements under high effort. For this reason, a transition from a knowledge-based to a functional-driven design approach is recommended [2-4]. Consequently, Lampl et al. [5] presented a functional-driven design approach ${ }^{2}$ for advanced FCS with multifunctional flight control devices ${ }^{3}$. The objective of this approach is to explore the potential design space and derive several solutions to enable the functional enhancement of the FCS [5]. Figure 1 illustrates the overall design process, which is dedicated for the conceptual and preliminary design of subsonic commercial transport aircraft.

For the architectural design of advanced FCS, two major aspects should be considered. Firstly, the functional enhancement of the FCS by using new technologies and concepts (e.g. cruise variable camber, active flow control). Secondly, the trend towards More-Electric Aircraft (MEA) with the evolutionary application of enabling electrical and electronic technologies leads to considerable changes

\footnotetext{
${ }^{1}$ The average probability for catastrophic failure conditions, for example the loss of roll or pitch control, should be extremely improbable ( $<10^{-9}$ per flight hour).

${ }^{2}$ The approach is based on the "Principle of the functional driven moveables [sic] approach"published by Reckzeh [2] in 2014.

3 Multifunctiona/ implies that flight control devices have (by design) or fulfil (by use) multiple flight control functions [5].
} 
on aircraft system level $[6,7]$. Both aspects lead to new technological constraints or additional options for the FCS architecture, which increase the design space to find valid solutions.

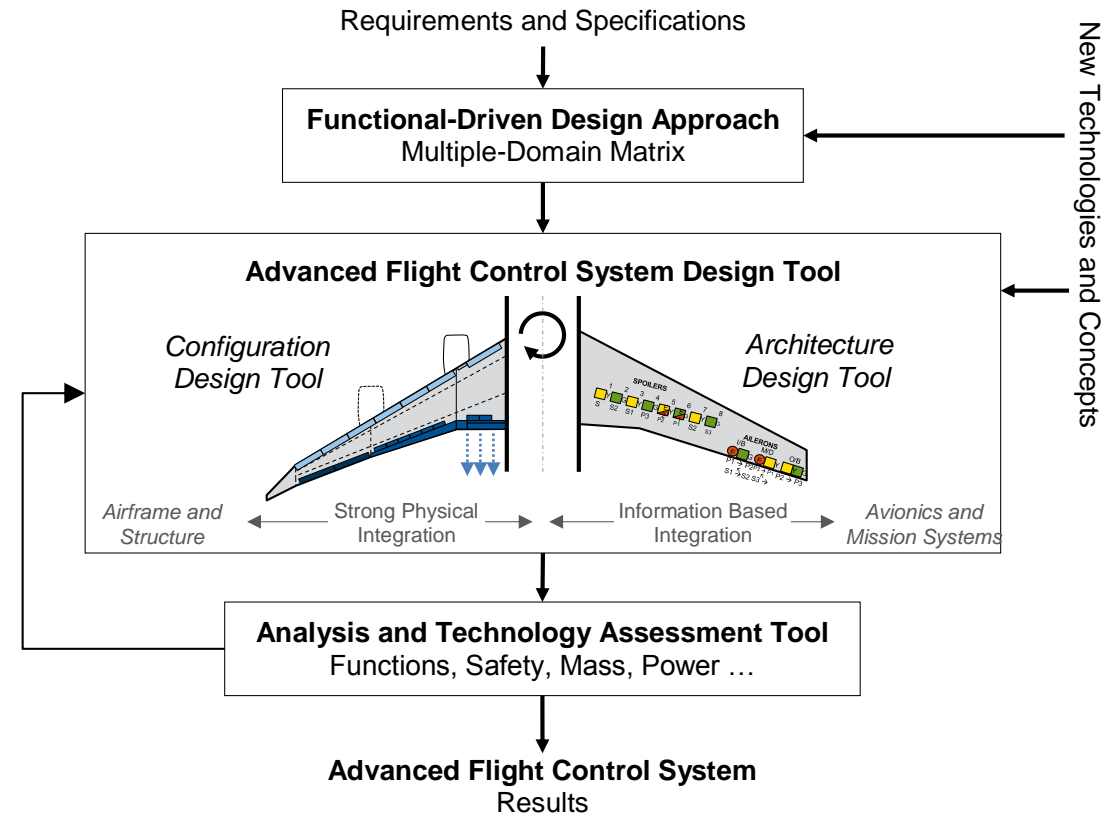

Figure 1: Overall design method for advanced flight control systems [5].

The objective of this contribution is to enable the preliminary design of advanced FCS architectures. Therefore, simplified models of the systems of the architecture are developed. Furthermore, technological assumptions are made and design rules for actuator distribution, power redundancy, and reconfiguration are defined. The main design rules are based on a comprehensive review of existing FCS architectures of Airbus and Boeing transport aircraft. Finally, the presented method will be implemented into $M A T L A B^{\circledR}$ by object-oriented programming. The resulting tool enables the preliminary design of an architecture for a given advanced FCS configuration for further analysis and sizing.

\section{BACKGROUND}

In this section the main requirements and constraints for Flight Control System (FCS) architectures is shown. Furthermore, the state of the art and design aspects for FCS architectures of commercial transport aircraft are presented. Finally, a brief overview on previous studies regarding FCS architecture design principles in early aircraft design phases is given.

\subsection{Flight Control System Requirements}

According to Lampl et al. [5], the FCS can be divided into a configurational system and architectural system. The FCS configuration describes the layout of the flight control devices, including the kinematics, supports, and the fairings. The flight control devices of the FCS are generally classified as primary or secondary, depending on their function and criticality. The flight-critical primary flight control devices (e.g. aileron, elevator, and rudder) are continuously activated to maintain safe attitude and trajectory control of the aircraft. Secondary flight control devices (e.g. high-lift control devices) are deployed intermittently or only during certain flight phases and thus, less critically for a safe flight. The FCS architecture, in terms of number of actuators, distribution of the power supply and Flight Control Computers (FCC), is primarily driven by safety considerations $[8,9]$. The fault tolerance and fault detection are key points in the design of FCS to withstand single or multiple failures, while maintaining the necessary level of safety [1]. For example, the complete loss of power supply for the flight control actuation systems should be extremely improbable $\left(10^{-9}\right)$. That's why a minimum of three independent power sources for the actuators of the primary flight control devices are required [10]. Dedicating standards and regulations are defined by the CS- 25 of the EASA and the FAR 25 of the FAA. 


\subsection{State-of-the-Art Flight Control Systems}

In general, there are different philosophies regarding the fly-by-wire FCS architecture of different manufacturers ${ }^{4}$. But to understand the main principles, the FCS architecture of the Airbus A320 should serve as a representing example, see Fig. 2 and Fig. 3. The electrical signaling of the actuators is done over two Primary Flight Computers (PFCC) and three Secondary Flight Computers (SFCC), with a defined reconfiguration order for automatic management following a failure. The signals for the high-lift control systems are provided by two high-lift control computers (HLCC). Each FCC controls and monitors the assigned actuators, or the drive systems of the high-lift control systems respectively. The evolution of Airbus fly-by-wire FCC from the A320 to the A350 show slightly different numbers and notations of the FCC. Nevertheless, the principle remains the same [12].

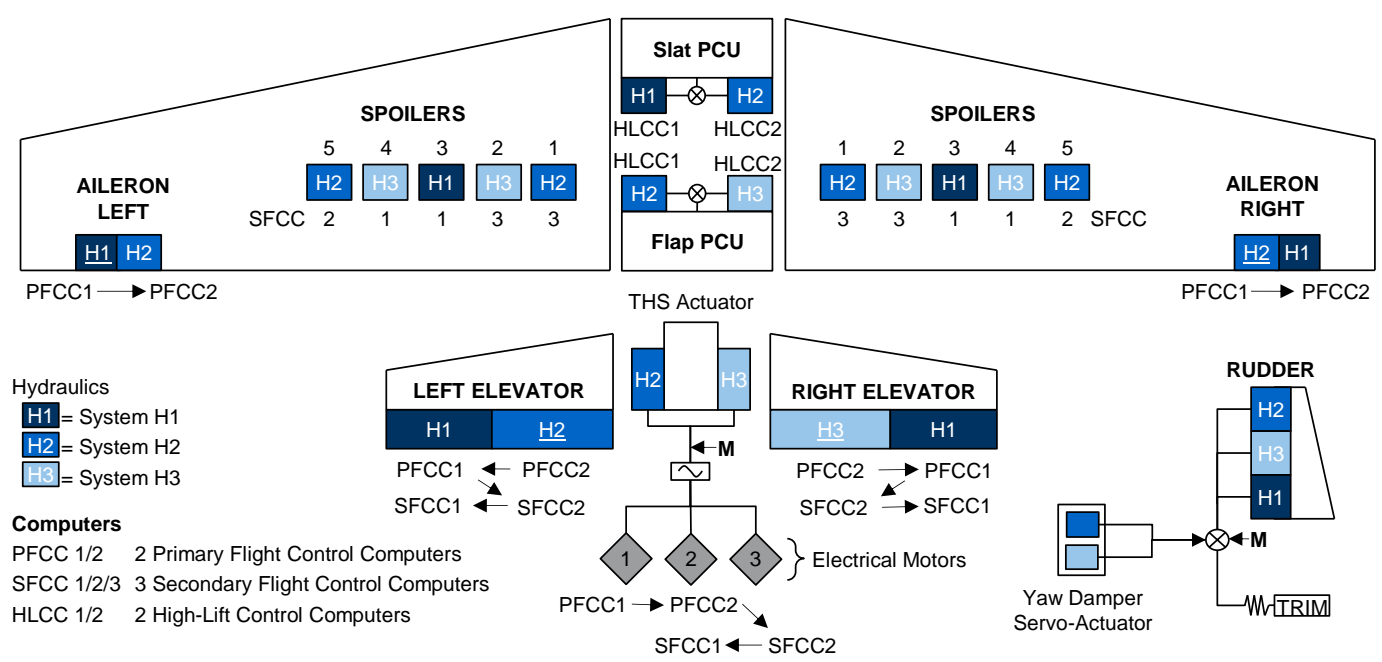

Figure 2: Flight control system architecture, modified from Wild [13] .

The three redundant hydraulic systems ${ }^{5}$ provide hydraulic power to the Servo-valve controlled Hydraulic Actuators (SHA). The defined distribution of the hydraulic systems and assignment of the actuators to the flight control devices still enables a safe operation of the FCS in the case of a failure of one or two hydraulic systems. The primary flight control devices are actuated by two (aileron, elevator) or three actuators (one-part rudder). Whereas each spoiler is actuated by a single actuator. The slats and flaps of the high-lift control system are powered over two central Power Control Units (PCU) and a mechanical transmission shaft system.

Figure 3 illustrates the simplified trailing edge flap actuation system of the Airbus A320. The slat actuation system (not shown) has a similar architecture. Rotary actuators operate the slats and flaps, which are driven over differential gear and transverse torque shafts.

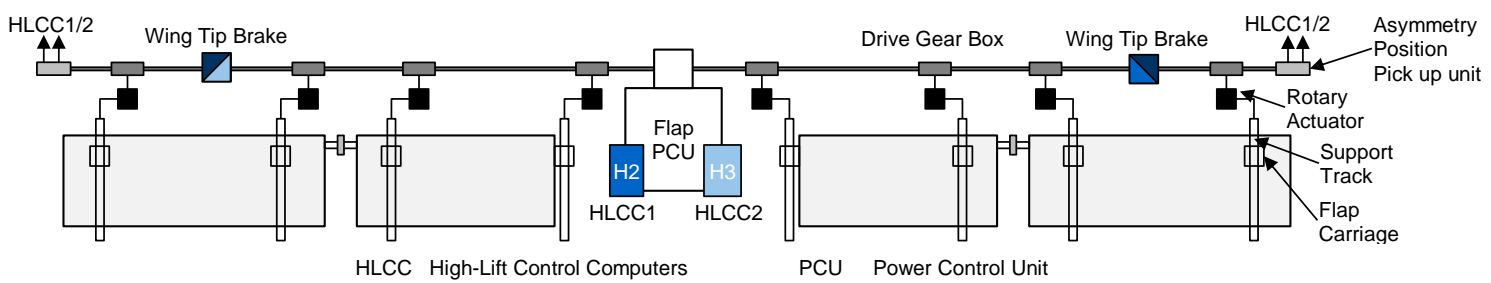

Figure 3: Trailing edge flap actuation system architecture, modified from Wild [13].

The wing tip brakes prevent asymmetric operation of the flaps, runaway or over-speed. The position pick-up units at the wing tips are used for detection of asymmetric operation and for system monitoring. According to Recksiek [3], the mechanical transmission shaft requires high design-engineering and installation effort and prohibits functional flexibility. Further improvements and functional enhancement

\footnotetext{
${ }^{4}$ A good explanation of the main differences between the Airbus, Boeing, and Liebherr-Aerospace approach for the fly-by-wire FCS architecture design is presented by Lammering et al. [11].

${ }^{5}$ Usually, the hydraulic systems are defined as Blue, Green, and Yellow (Airbus) or Left, Center, and Right (Boeing). In this study, a more general notation is used and the hydraulic systems are defined as $\mathrm{H1}, \mathrm{H} 2$, and $\mathrm{H} 3$.
} 
are expected by different concepts of advanced high-lift control systems with distributed electrical flap actuation $[3,14]$.

The trend towards MEA and the introduction of new electrical technologies and concepts lead to substitutions of some hydraulic and pneumatic systems. Figure 4 shows common power generation and distribution architectures, regarding the FCS power supply. The architectures generally can be defined either as $3 \mathrm{H}$ or as a $2 \mathrm{H}-2 \mathrm{E}$ architecture and have a major impact on the FCS architecture design. With respect to a possible integration of future Active Flow Control (AFC) systems, the presence of a bleedair system for pressurized air supply could be also relevant ${ }^{6}$.

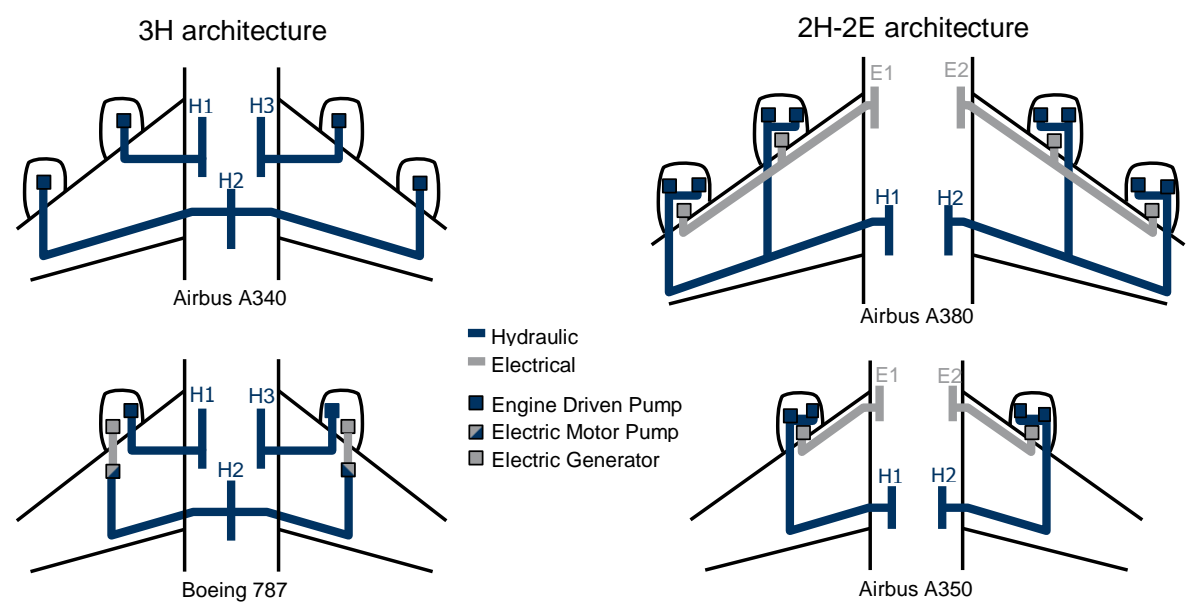

Figure 4: Generic primary power generation and distribution architectures.

Currently, four different types of actuators, which mainly differ in type of power supply and actuation drive unit are used. The default actuators used for FCS are Servo-valve Hydraulic Actuators (SHA). An evolutionary electrical development is the Electro-Hydrostatic Actuator (EHA), which combines the advantages of both electrical power (on demand) and hydraulic actuation (e.g. no jamming). The Electrical Backup Hydraulic Actuator (EBHA) combines the features of a conventional SHA (primary) and an EHA (backup).

Table 1: Main actuator types for flight control system tasks, modified from [12].

\begin{tabular}{|c|c|c|c|c|}
\hline Actuator Type & Power Source & Drive Unit & Actuation & Flight Controls \\
\hline $\begin{array}{l}\text { Servo-valve Hydraulic } \\
\text { Actuator (SHA) }\end{array}$ & $\begin{array}{l}\text { Hydraulic } \\
\text { System }\end{array}$ & $\begin{array}{l}\text { Hydraulic fluid } \\
\text { (SV* controlled) }\end{array}$ & Hydraulic actuator & $\begin{array}{l}\text { Aileron, Elevator, } \\
\text { Rudder, Spoiler }\end{array}$ \\
\hline $\begin{array}{l}\text { Electro-Hydrostatic } \\
\text { Actuator (EHA) }\end{array}$ & $\begin{array}{l}\text { Electrical } \\
\text { System }\end{array}$ & $\begin{array}{l}\text { Electric motor + } \\
\text { hydraulic pump }\end{array}$ & Hydraulic actuator & $\begin{array}{l}\text { Aileron, Elevator, } \\
\text { Rudder, Spoiler }\end{array}$ \\
\hline $\begin{array}{l}\text { Electrical Backup } \\
\text { Hydraulic Actuator (EBHA) }\end{array}$ & $\begin{array}{l}\text { Hyd. (primary) } \\
\text { Elec. (backup) }\end{array}$ & $\begin{array}{l}\text { Hydraulic fluid (SV) } \\
\text { Electric motor + } \\
\text { hydraulic pump }\end{array}$ & Hydraulic actuator & $\begin{array}{l}\text { Aileron, Elevator, } \\
\text { Rudder, Spoiler }\end{array}$ \\
\hline $\begin{array}{l}\text { Electro-Mechanical } \\
\text { Actuator (EMA) }\end{array}$ & $\begin{array}{l}\text { Electrical } \\
\text { System }\end{array}$ & $\begin{array}{l}\text { Electric motor + } \\
\text { gearbox }\end{array}$ & Ballscrew actuator & $\begin{array}{l}\text { THS**, Slats, Flaps, } \\
\text { Spoiler }\end{array}$ \\
\hline
\end{tabular}

${ }^{*}$ SV Servo Valve

**THS Trimable Horizontal Stabilizer

The main benefits of electric powered actuation are the weight reduction due to fewer hydraulic components, improved performance due to engine power-offtake on demand and low maintenance costs, compared to hydraulic actuation. Due to the certain single-point failures that can lead to a mechanical jam, the EMAs are not used for primary (flight-critical) actuation applications [6].

\footnotetext{
${ }^{6}$ Meyer et al. [15] present a possible implementation of a trailing edge flap with an active flow control (AFC) system to increase the high-lift performance of a commercial transport aircraft. The two-stage AFC system is solely powered by pressurized air of the engine bleed-air system and was successfully tested during system ground tests.
} 


\subsection{Architectural Design Aspects}

Based on the presented state-of-the-art of flight control systems, several architectural design aspects can be derived. To enable fault-tolerant FCS, the principle techniques of redundancy, dissimilarity and segregation (among others) are required [1]:

- Redundancy is the multiplication of flight critical components or functions of the safety-critical system with the intention of increasing reliability of the system (backup or fail-safe). Redundancy within the FCS design enables the capability of reconfiguration, which is a key point for a fault tolerant system.

- Dissimilarity increases the robustness to common-mode faults by using dissimilar hardware and/or dissimilar software, with the objective to tolerate a (unknown) design error of the system. An example for dissimilarity is the application of different types of actuators for the same control surface.

- Installation segregation is applied for critical system/components (e.g. FCC) and hydraulic/electrical routes, to avoid the loss of several functionalities due to a single failure (e.g. engine burst).

As this contribution aims on the design of FCS architectures in early aircraft design phases with limited available system details, the focus is on hardware redundancy and dissimilarity.

\subsection{Previous Studies}

Following research studies present an approach for the design or analysis of FCS architectures of commercial transport aircraft:

Bauer et al. [16], present a tool for the design and optimization of FCS architectures for commercial transport aircraft at early aircraft design phases, considering More-Electric Aircraft (MEA) technologies ${ }^{7}$. In this research study, technological constraints and in-house design rules are applied to reduce the number of initial solutions. Finally, a discrete optimization algorithm finds an optimal architecture regarding minimum system weight, thus fulfilling the safety constraints. However, the tool is used as a decision-analysis tool and is limited to mainly knowledge-based FCS designs [16].

In the research study of Kreitz et al. [4] a simulation-driven methodology for the assessment of innovative flight control system is presented. The first step of the methodology is the flight dynamics analysis, which is further divided into handling quality and flight performance analysis. Afterwards, in a second step, the safety assessment of the FCS, in form of Functional Hazard Assessment (FHA) and Preliminary System Safety Assessment (PSSA) is conducted. Several input parameters such as aircraft configuration, the FCS configuration and functional allocation of the flight control surfaces are required. Nevertheless, the handling quality and flight performance analysis requires a complex nonlinear simulation model representing the aircraft [4].

A requirements-driven methodology for MEA to integrate aircraft systems in early aircraft design phases - including electric flight control actuation system architectures - is presented by Chakraborty et al. [7]. In this contribution, two different electrical actuation architectures using Electro-Hydrostatic Actuators (EHA) and Electro-Mechanical Actuators (EMA) for one FCS configuration are sized and analyzed on aircraft and mission level [7]. A possible functional enhancement of the FCS or new enabling technologies or concepts are not considered.

\section{PRELIMINARY DESIGN OF FLIGHT CONTROL SYSTEM ARCHITECTURES}

Based on the literature review and state-of-the-art FCS of commercial transport aircraft, the system boundary of the FCS architecture for preliminary design can be defined as illustrated in Fig. 5. The main characteristics of the FCS architecture can be described by the FCC unit, the actuation system, and the power supply distribution. In this study, the simplified FCC unit consists of three primary and two secondary $\mathrm{FCCs}^{8}$, and two HLCCs. The actuation system defines all actuators required for the flight control devices of the FCS configuration, including the PCUs and actuation system of the high-lift control

\footnotetext{
${ }^{7}$ Bauer et al. [16] consider also a $2 \mathrm{H}-2 \mathrm{E}$ architecture for the power supply distribution, and the Electro-Hydrostatic Actuator (EHA) and Electrical-Backup Actuator (EBHA) for flight control surfaces.

${ }^{8}$ Nevertheless, the different philosophies of the fly-by-wire FCS architecture FCC described by Lammering et al. [11] can still be considered in detail design.
} 
system. The power supply distribution describes the assignment of different power sources to the actuators and PCUs. Furthermore, the main interfaces for the input of the pilot or autopilot, aircraft feedback, and for the device actuation are required. The design of the FCS architecture is mainly driven by functional and safety requirements. Whereas technological constraints and top-level aircraft system architectures restrict the design space.

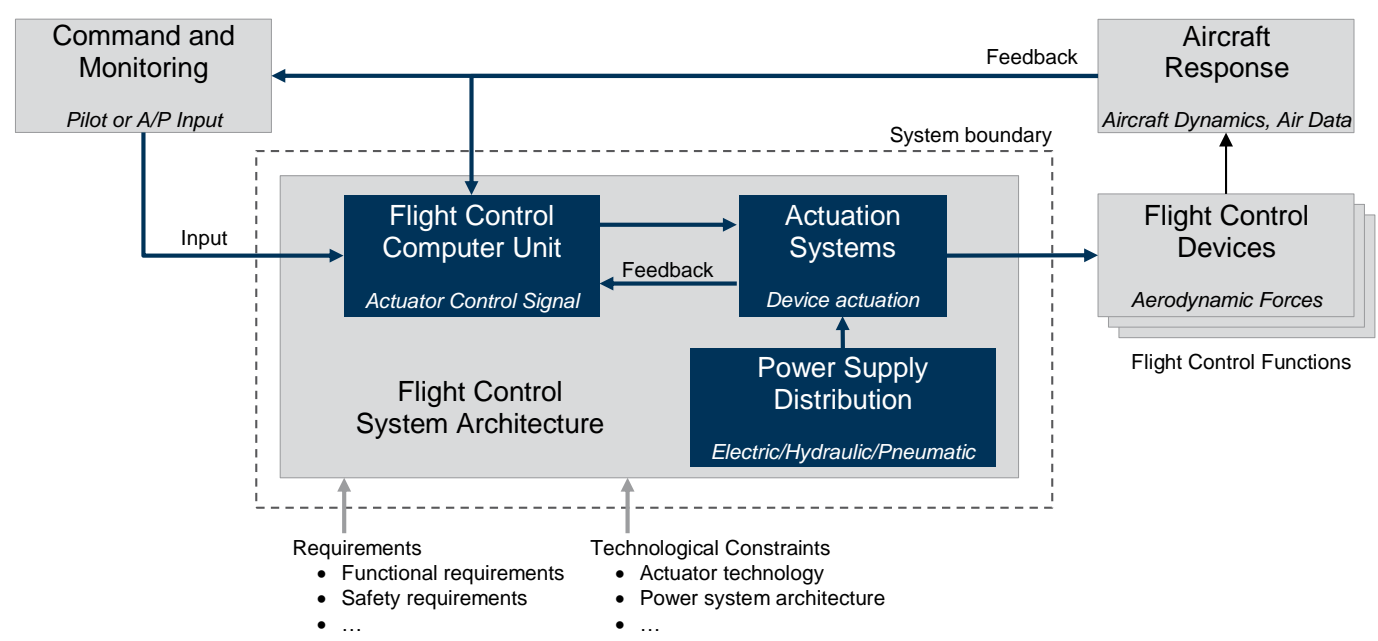

Figure 5: Schematic flight control system architecture and the system boundary.

In summary, it can be stated, that a wealth of information should be handled to find a technological suitable architecture in early aircraft design phases.

\subsection{Design Method}

The design method for the preliminary design of FCS architectures is based on a top-down approach, illustrated in Fig. 6. The input data for the preliminary design tool is a FCS configuration, consisting of arranged flight control devices and dimensioning loads or hinge moments. Due to the very different design aspects of the primary flight control devices and spoilers, and the high-lift control system, the top-down approach is separated. On the one hand, the actuator types are selected and arranged to the dedicated flight control devices. On the other hand, the high-lift control system characteristics define the kinematic and actuation requirements, including the transmission shaft and PCU. Afterwards, the FCCs are assigned to each flight control device per defined redundancy and reconfiguration rules. The distribution logics defines the power supply assignment to each flight control device and its actuator(s), and completes the architectural design.

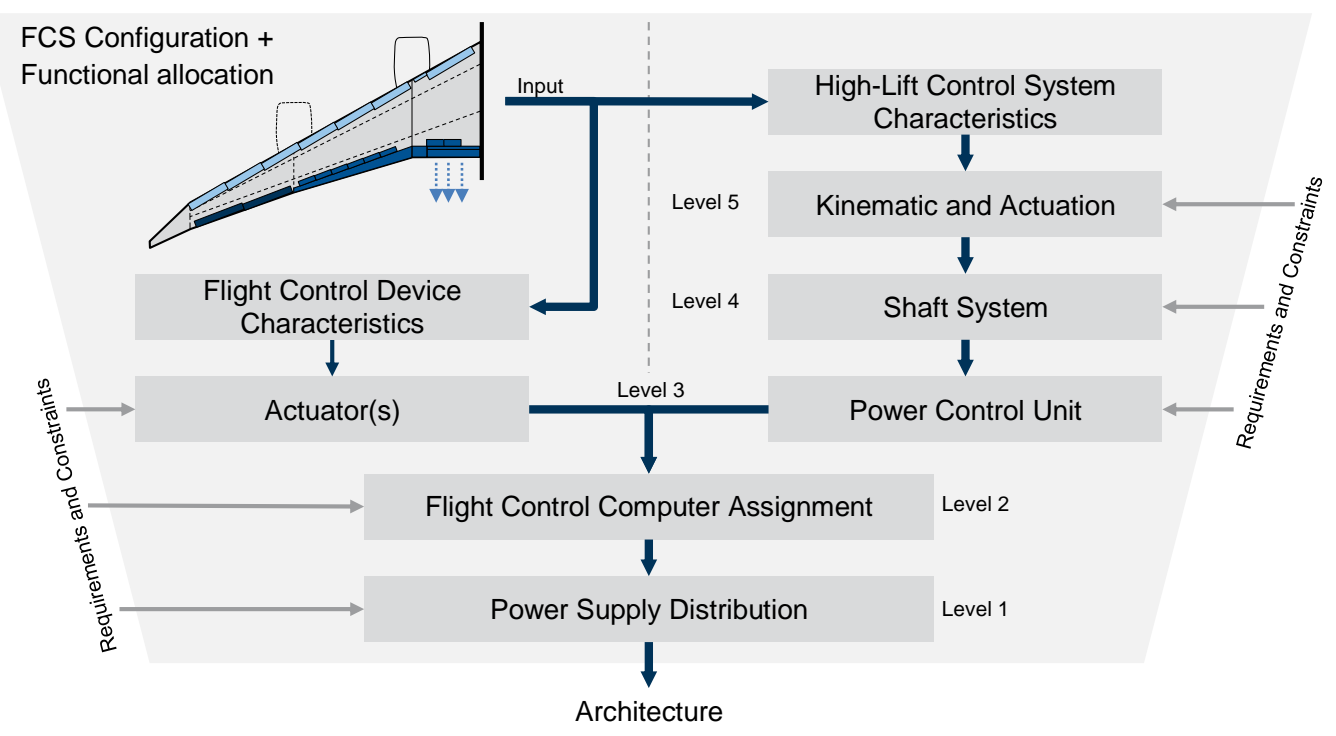

Figure 6: Top-down design approach for flight control system architectures. 
The approach is implemented in MATLAB ${ }^{\circledR}$ using object-oriented programming. The subsystems are defined as classes with system-specific properties (e.g. technology, interfaces and failure rates) and functions. Furthermore, within the implemented method, all technological relevant designs of the subsystems are pre-defined as objects. For example, the SHA is defined as an instance of the class Actuator and filled with architecture-independent properties.

The specific design of each subsystem of level 3 to 5 show strong dependability to the properties and characteristics of the respectively higher level subsystem (see Fig. 7). Therefore, the technological constraints and the rules for interface definition between two subsystems are defined in the higherlevel subsystem. After subsystem level 3, the FCC assignment (level 2) and power supply distribution (level 1) are strongly dependent on the subsystem properties of the same level. Therefore, the interface definitions for the FCC and power supply in level 2 and 1 are defined in the class Architecture.

\subsection{Design Rules}

Technological constraints for the FCS architecture are primarily defined by the FCS configuration and the overall aircraft system architecture (e.g. MEA, 2H-2E, no-bleed). According to the findings of the background section and the general design rules published by Bauer et al. [16], following main technological constraints can be defined:

\section{Actuation System}

- All actuators must be connected to the appropriate types of power source(s).

- Flight critical flight control devices should be actuated by at least two actuators (e.g. activepassive mode).

- No EMAs for flight-critical devices are allowed.

\section{Power Supply and Flight Control Computers}

- $\quad$ Each PCU is powered by two different power sources.

- The FCC unit consists of three PFCCs, three SFCCs and two HLCCs.

- All actuators on a same flight control device should have different power sources and/or FCCs.

- Flight-critical actuators should be connected to at least two different FCCs for reconfiguration.

\section{Overall Flight Control System Architecture}

- Two or more ailerons (on one wing) next to each other should have different architectures (regarding power sources and FCCs).

- Power sources and FCCs should be evenly distributed to have a comparable load and number of tasks, respectively.

Based on these technological constraints, following basic design rules for conventional FCS architectures can be derived, see Table 2. The main control functions are identified and classified as flight-critical or not. Afterwards, the actuators are distributed to the dedicating flight control surfaces and their control function(s). Finally, the power supply and the FCCs are assigned by defined rules.

Table 2: Design rules for conventional flight control system architectures.

\begin{tabular}{|c|c|c|c|c|c|c|}
\hline $\begin{array}{l}\text { Control } \\
\text { Function(s) }\end{array}$ & $\begin{array}{l}\text { Flight } \\
\text { Critical }\end{array}$ & $\begin{array}{l}\text { Control } \\
\text { Surface }\end{array}$ & $\begin{array}{l}\text { No. } \\
\text { Actuators }\end{array}$ & $\begin{array}{l}\text { Power Supply } \\
\text { Distribution }\end{array}$ & $\begin{array}{l}\text { Flight Control } \\
\text { Computer (FCC) }\end{array}$ & $\begin{array}{l}\text { FCC } \\
\text { Assignment }\end{array}$ \\
\hline Roll control & yes & Aileron & 2 & symmetrical $^{\mathrm{W}}$ & PFCC, SFCC ${ }^{B}$ & enumerate \\
\hline Pitch control & yes & Elevator & 2 & enumerate & PFCC, SFCC ${ }^{B}$ & symmetrical \\
\hline Yaw control & yes & Rudder (1/2) & $3 / 2$ & enum./sym. & PFCC, SFCC ${ }^{B}$ & enum./sym. \\
\hline Trim & no & THS & 3 & enumerate & PFCC, SFCC ${ }^{B}$ & enumerate \\
\hline Airbrake/Lift Dump & no & Spoiler & 1 & symmetrical $^{\mathrm{W}}$ & PFCC, SFCCA & symmetrical ${ }^{\mathrm{W}}$ \\
\hline High-lift control & no & LE Flaps & $1(\mathrm{PCU})$ & enumerate & HLCC & enumerate \\
\hline High-lift control & no & TE Flaps & 1 (PCU) & enumerate & HLCC & enumerate \\
\hline $\begin{array}{l}\text { LE Leading Edge (wing } \\
\text { TE Trailing Edge (wing) } \\
\text { THS Trimable Horizontal }\end{array}$ & & $\begin{array}{ll}\text { HLCC } & \text { High-Lif } \\
\text { PFCC } & \text { Primary } \\
\text { SFCC } & \text { Second }\end{array}$ & $\begin{array}{l}\text { light Control Com } \\
\text { y Flight Control C }\end{array}$ & $\begin{array}{l}\text { outer } \\
\text { mputer }\end{array}$ & $\begin{array}{l}\text { A Alternately PFCC and } \\
\text { B Backup } \\
\text { w Wing-symmetric (left/r }\end{array}$ & \\
\hline
\end{tabular}




\section{CASE STUDY AND PRELIMINARY RESULTS}

In this section, a brief case study is conducted to validate the FCS architecture design tool and the basic design rules. Therefore, the conventional FCS architecture of a generic transport aircraft is generated. Afterwards, further design rules are derived for the architecture design of advanced FCS with multifunctional flight control devices.

\subsection{Conventional Flight Control System Architectures}

Figure 7 and 8 show the results of the FCS architectures powered by a $3 \mathrm{H}$ and a $2 \mathrm{H}-2 \mathrm{E}$ architecture, respectively. For both architectures, a FCC unit consisting of three PFCCs, three secondary PFCCs, and two HLCCs is considered. The FCS powered by the $3 \mathrm{H}$ architecture exclusively uses SHAs powered by one hydraulic power source. Whereas, the more-electric $2 \mathrm{H}-2 \mathrm{E}$ architecture enables the application of three different actuators; the SHA, EHA, and EBHA. The EHA is powered by one electrical power circuit. Whereas the EBHA requires hydraulic power source for primary supply, and an electrical power source as backup.

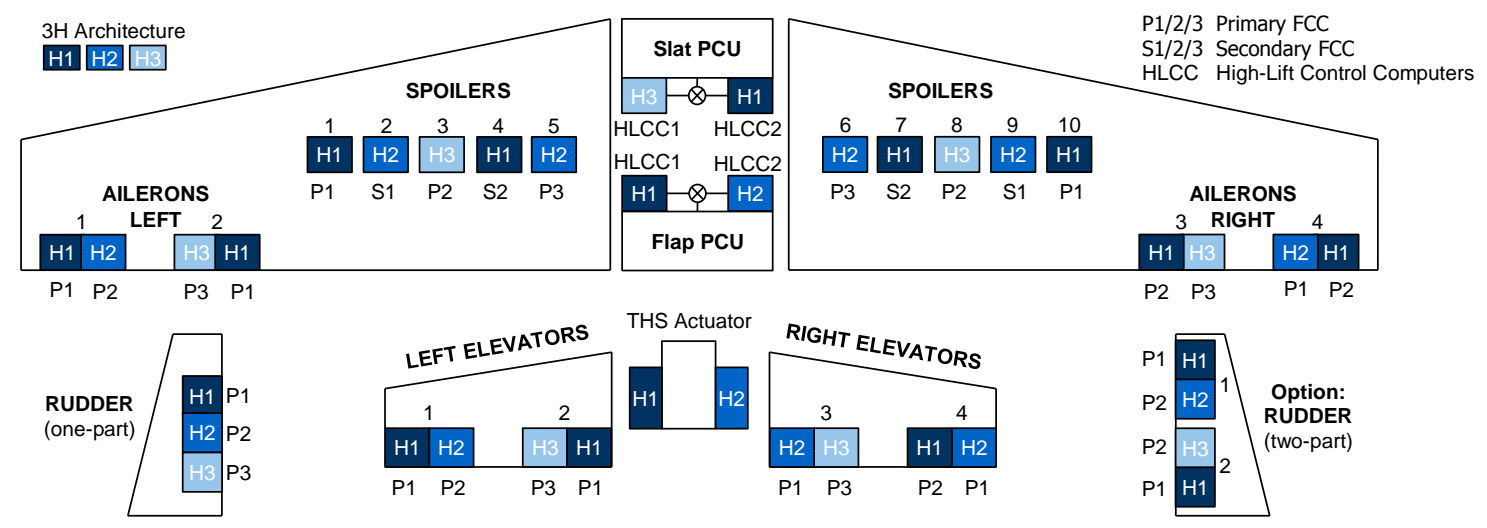

Figure 7: Conventional flight control system architecture powered by three hydraulic power circuits $(3 \mathrm{H})$.

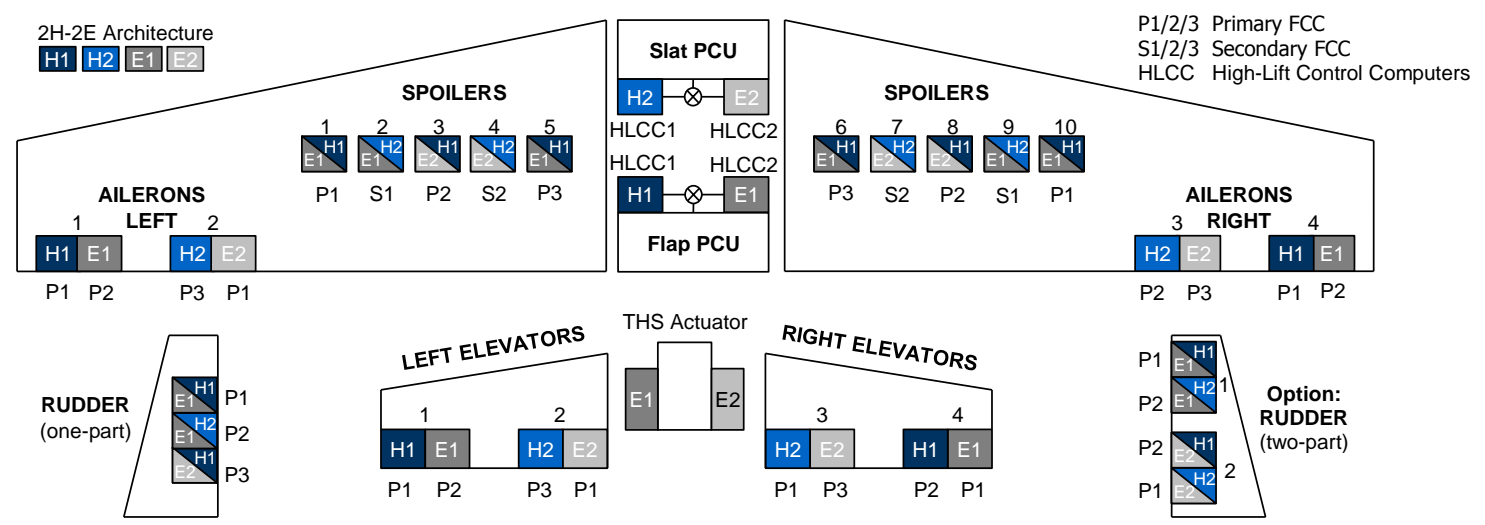

Figure 8: More-electric flight control system architecture powered by two hydraulic power circuits and two electrical power circuits (2H-2E).

The hydraulic power supplies of the left ailerons are distributed by means of counting and then mirrored to the right wing, to achieve a symmetrically design. The assignment of the primary $\mathrm{FCCS}^{9}$ is also defined by means of counting for all ailerons (1-4) of the wing. This ensures the required dissimilarity of the aileron actuation system, and consequently a redundant design of the roll control architecture.

The spoiler actuation architecture is also wing-symmetric. Whereas the power supply for the spoilers on one side of the wing are distributed by means of counting, with alternately assigned PFCCs and SFCCs. Two options are considered for the yaw control: a one-part rudder and a two-part rudder. The

${ }^{9}$ For a better illustration in Fig. 7 and Fig. 8, the three PFCCs and SFCCs are abbreviated as P1, P2, P3 and S1, S2, S3, respectively. 
design rules for the power supply distribution for the rudder actuation stays the same, but the FCC assignment is different: counting (enumerate) for the one-part rudder and symmetrical for the twopart rudder. For all other flight control devices, the defined design rules of Table 2 are applied.

Finally, it can be stated, that the preliminary results show good accordance to the state-of-the-art FCS architectures of commercial transport aircraft.

\subsection{Advanced Flight Control System Architectures}

The principles of the functional allocation on the wing for a conventional and advanced FCS are schematically illustrated in Fig. 9. The conventional FCS consists of mainly mono-functional flight control devices fulfilling the basic flight control functions. Whereas the multifunctional flight control devices of advanced FCS enable new control functions or support the basic flight control functions. For example, a trailing edge flap with active flow control can be used for high-lift control, for differential flap setting or for cruise variable camber. In general, flight control devices are defined as movables, surfaces, or technologies which are providing or supporting control functions [5].

Conventional Flight Control System

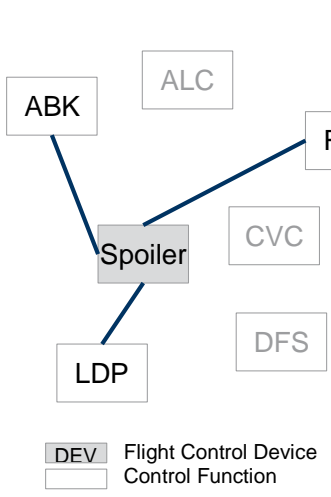

\section{Aileron}

RLC
Flap

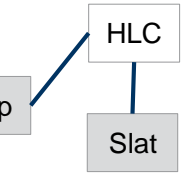

Advanced Flight Control System

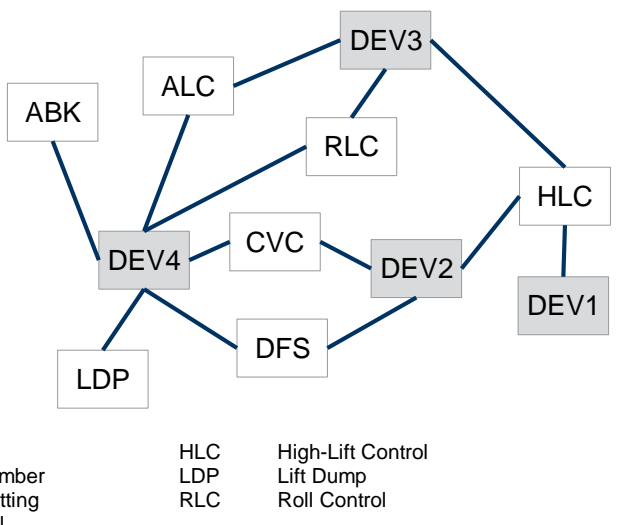

Figure 9: Simplified functional allocation of a conventional (left) and an advanced (right) flight control system (wings only), modified from [5].

Based on the basic design rules of conventional FCS, additionally design rules can be derived for advanced FCS with multifunctional flight control devices. Table 3 show the flight control devices with the required characteristics to fulfil the different control functions. Even if the control devices shown here are known, the control functions can be fulfilled by different types of control devices collectively or individually. Accordingly, future flight control devices of advanced FCS are might be differently named ${ }^{10}$.

\section{Table 3: Additional design rules for advanced flight control system architectures.}

\begin{tabular}{|c|c|c|c|c|c|}
\hline $\begin{array}{l}\text { Advanced Control } \\
\text { Function(s) }\end{array}$ & $\begin{array}{l}\text { Control } \\
\text { Device(s) }\end{array}$ & $\begin{array}{l}\text { Control Device } \\
\text { Characteristics }\end{array}$ & $\begin{array}{l}\text { Power Supply } \\
\text { Distribution }\end{array}$ & $\begin{array}{l}\text { Flight Control } \\
\text { Computer (FCC) }\end{array}$ & $\begin{array}{l}\text { FCC } \\
\text { Assignment }\end{array}$ \\
\hline Roll controls & $\begin{array}{l}\text { Flaperon } \\
\text { Spoiler }\end{array}$ & $\begin{array}{l}\text { Deflection up/down } \\
\text { Deflection up/down }\end{array}$ & symmetrical $^{\mathrm{W}}$ & $\begin{array}{l}\text { PFCC, SFCC } \\
\text { PFCC, SFCC }\end{array}$ & $\begin{array}{l}\text { enumerate } \\
\text { enumerate }\end{array}$ \\
\hline High-lift controls & $\begin{array}{l}\text { Aileron } \\
\text { Flaperon } \\
\text { AFC }^{F}\end{array}$ & $\begin{array}{l}\text { Deflection down } \\
\text { Deflection down } \\
\text { Fluidic actuators on }\end{array}$ & symmetrical $^{\mathrm{W}}$ & PFCC, SFCC ${ }^{\mathrm{B}}$ & enumerate \\
\hline Active load control & $\begin{array}{l}\text { Aileron } \\
\text { Spoiler }\end{array}$ & $\begin{array}{l}\text { Deflection up/down } \\
\text { Deflection up/down }\end{array}$ & symmetrical $^{\mathrm{W}}$ & PFCC, SFCC ${ }^{B}$ & enumerate \\
\hline Differential flap setting & TE Flaps & Deflection up/down & enumerate & HLCC & enumerate \\
\hline Cruise variable camber & $\begin{array}{l}\text { TE Flaps } \\
\text { Spoiler }\end{array}$ & $\begin{array}{l}\text { Deflection up/down } \\
\text { Deflection down }\end{array}$ & enumerate & $\begin{array}{l}\text { HLCC } \\
\text { PFCC, SFCC }\end{array}$ & $\begin{array}{l}\text { enumerate } \\
\text { symmetrical }^{\mathrm{w}}\end{array}$ \\
\hline $\begin{array}{l}\text { AFC Active Flow Control } \\
\text { TE Trailing Edge (wing) }\end{array}$ & $\begin{array}{ll}\text { HLCC } & H \\
\text { PFCC } & P \\
\text { SFCC } & S\end{array}$ & $\begin{array}{l}\text { rol Computer } \\
\text { Control Computer } \\
\text { ght Control Computer }\end{array}$ & $\begin{array}{ll}\text { B } & \text { Backup } \\
\text { F } & \text { Fluidic Actuation ( } \\
\text { G } & \text { Gap control (b/t fl }\end{array}$ & $\begin{array}{l}\text { g. two-stage) } \\
\text { and spoiler) }\end{array}$ & $\begin{array}{l}\text { Pulsed jet } \\
\text { portive } \\
\text { g-symmetric (left/right) }\end{array}$ \\
\hline
\end{tabular}

${ }^{10}$ For example, known flight control surfaces with blended control functions are so called flaperons, tailerons, or elevons. 
To get an idea of advanced FCS architectures, a simplified actuation architecture of multifunctional flight control devices on the wings and their functional allocation are illustrated in Fig. 10. The roll control actuation architecture includes the ailerons, flaperons, and most of the spoilers on both wings. Whereas the high-lift control function is mainly provided by the slat and flap actuation system, but is supported by drooped ailerons or flaperons.

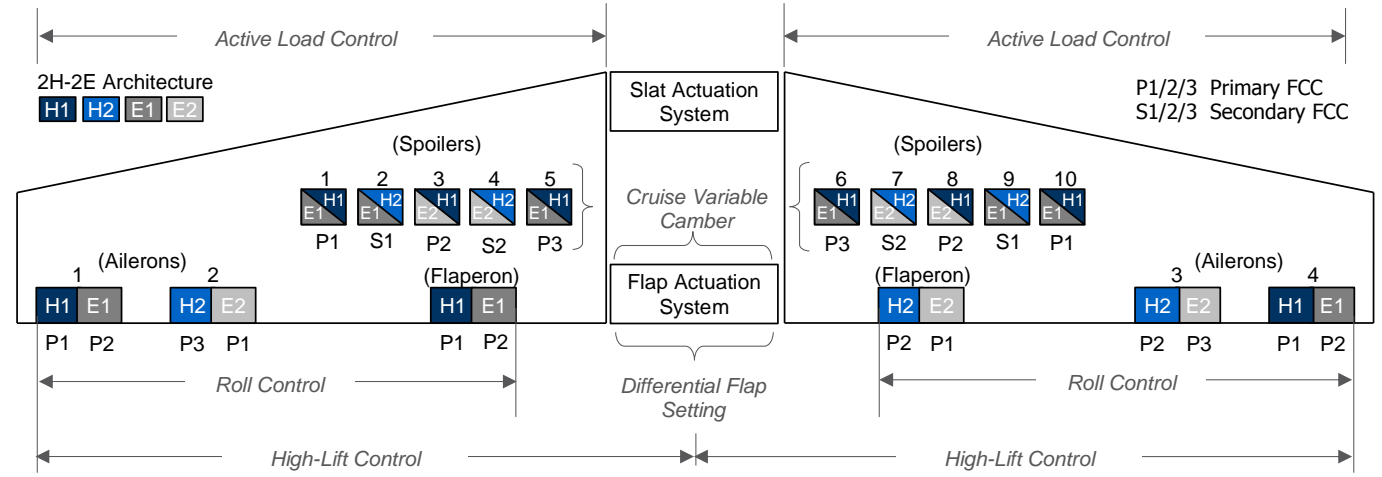

\section{Figure 10: Architecture of a generic advanced flight control system with multifunctional flight control devices (wings only).}

The cruise variable camber function can be fulfilled by small deflections of the trailing edge flaps and drooped spoilers to close the gap. Furthermore, the downward deflection can be used for gap control between the trailing edge and the leading edge of the flap. The differential flap setting function for wing load control is solely fulfilled by the trailing edge flaps and its actuation system (not shown in detail). In this case of functional enhancement, it would probably be beneficial to have a distributed flap actuation system instead of a traditional shaft transmission system. Furthermore, new technologies for flight control devices probably have several options for the power supply. For example, an AFC system with fluidic actuation for trailing edge flaps requires pressurized air supply, which can be provided by the bleed air system or by electrically powered compressors. Consequently, different concepts of actuation systems or required power supply provide different design spaces.

\section{CONCLUSION}

The design of Flight Control System (FCS) architectures of commercial transport aircraft are mainly driven by safety aspects. Furthermore, two major aspects should be considered for future FCS architectures: the functional enhancement of the FCS with multifunctional flight control devices and the trend towards More-Electric Aircraft (MEA). Consequently, this study contributes to a preliminary design method for advanced FCS architectures, to explore the potential design space in early aircraft design phases.

Based on a comprehensive literature review of existing FCS architectures of commercial transport aircraft and previous studies, the technological constraints are discussed, and subsequently several design rules defined. The technological constraints and design rules are primarily driven by the FCS configuration (e.g. layout) and the overall aircraft system architecture (e.g. MEA). Therefore, a simplified system model is defined, including the Flight Control Computer (FCC) unit, the actuation systems, and the power supply distribution, to generally describe the FCS architecture. The resulting design method is based on a top-down approach and implemented into MATLAB ${ }^{\circledR}$, where the main subsystems are defined as classes with system-specific properties (object-oriented programming).

The preliminary FCS architectures of a generic aircraft with a conventional FCS powered by a $3 \mathrm{H}$ and a $2 \mathrm{H}-2 \mathrm{E}$ architecture, show good accordance to architectures found in literature. Based on the results and further design rules, an illustrative example of an advanced FCS architecture with the functional allocation is presented. Finally, it can be stated, that the developed design method enables the preliminary design of advanced FCS architectures, based on technological constraints and defined design rules.

For the future, the integration of a mass estimation is planned and the development of a method to finally evaluate the found FCS architectures. 


\section{REFERENCES}

1. Goupil, P.: AIRBUS state of the art and practices on FDI and FTC in flight control system. Control Engineering Practice (2011). doi: 10.1016/j.conengprac.2010.12.009

2. Reckzeh, D.: Multifunctional Wing Moveables: Design of the A350XWB and the Way to Future Concepts. In: International Council of Aeronautical Sciences (ICAS) (ed.) 29th Congress of the International Council of the Aeronautical Sciences, St. Petersburg, Russia (2014)

3. Recksiek, M.: Advanced High Lift System Architecture with Distributed Electrical Flap Actuation. In: Estorff, O. von (ed.) Proceedings of the 2nd International Workshop on Aircraft System Technologies. March 26 - 27, 2009, Hamburg, Germany. Berichte aus der Luft- und Raumfahrttechnik, pp. 49-60. Shaker, Aachen (2009)

4. Kreitz, T., Bornholdt, R., Krings, M., Henning, K., Thielecke, F.: Simulation-Driven Methodology for the Requirements Verification and Safety Assessment of Innovative Flight Control Systems. In: SAE 2015 AeroTech Congress \& Exhibition, SEP. 22, 2015. SAE International, Warrendale, PA, United States (2015). doi: 10.4271/2015-01-2478

5. Lampl, T., Sauterleute, D., Hornung, M.: A Functional-Driven Design Approach for Advanced Flight Control Systems of Commercial Transport Aircraft. In: Estorff, O. von, Thielecke, F. (eds.) Proceedings of the 6th International Workshop on Aircraft System Technologies. February 21-22, 2017, Hamburg, Germany. Berichte aus der Luft- und Raumfahrttechnik, 1st edn., pp. 3-12. Shaker, Herzogenrath (2017)

6. Botten, S.L., Whitley, C.R., King, A.D.: Flight Control Actuation Technology for NextGeneration All-Electric Aircraft. Technology Review Journal, 55-68 (2000)

7. Chakraborty, I., Mavris, D.N., Emeneth, M., Schneegans, A.: A methodology for vehicle and mission level comparison of More Electric Aircraft subsystem solutions. Application to the flight control actuation system. Proceedings of the Institution of Mechanical Engineers, Part G: Journal of Aerospace Engineering (2015). doi: 10.1177/0954410014544303

8. Traverse, P., Lacaze, I., Souyris, J.: Airbus Fly-By-Wire. A Total Approach To Dependability. In: Jacquart, R. (ed.) Building the Information Society, vol. 156. IFIP International Federation for Information Processing, pp. 191-212. Springer US, Boston, MA (2004)

9. Traverse, P., Lacaze, I., Souyris, J.: Airbus Fly-By-Wire. A Process Toward Total Dependability. In: International Council of Aeronautical Sciences (ICAS) (ed.) 25th Congress of the International Council of the Aeronautical Sciences, Hamburg, Germany (2006)

10. Van Den Bossche, Dominique: The A380 Flight Control Electrohydrostatic Actuators, Achievements and Lessons Learnt. In: International Council of Aeronautical Sciences (ICAS) (ed.) 25th Congress of the International Council of the Aeronautical Sciences, Hamburg, Germany (2006)

11. Lammering, T., Weber, G.: Liebherr State-of-the-Art Fly-By-Wire Flight Control System for Commercial Transport Aircraft. In: Estorff, O.v., Thielecke, F. (eds.) Proceedings of the 4th International Workshop on Aircraft System Technologies. April 23-24, 2013, Hamburg, Germany, pp. 127-137. Shaker, Aachen (2013). doi: 10.1002/9781118403259.ch1

12. Moir, I., Seabridge, A.G.: Aircraft systems. Mechanical, electrical, and avionics subsystems integration, 3rd edn. Aerospace series. Wiley, Chichester, West Sussex, England, Hoboken, NJ (2008)

13. Wild, T.W.: Transport category aircraft systems. An IAP, Inc. training manual. IAP, Inc, Casper, WY (1990)

14. Lampl, T., Königsberger, R., Hornung, M.: Design and Evaluation of Distributed Electric Drive Architectures for High-Lift Control Systems. In: Deutsche Gesellschaft für Luft- und Raumfahrt (DGLR), Deutsche Gesellschaft für Luft- und Raumfahrt (DGLR) (eds.) 66. Deutsche Luft- und Raumfahrtkongress, München, Germany (2017)

15. Meyer, M., Machunze, W., Bauer, M.: Towards the Industrial Application of Active Flow Control in Civil Aircraft - An Active Highlift Flap. In: 32nd AIAA Applied Aerodynamics Conference. AIAA AVIATION Forum. American Institute of Aeronautics and Astronautics (2014)

16. Bauer, C., Lagadec, K., Bès, C., Mongeau, M.: Flight Control System Architecture Optimization for Fly-By-Wire Airliners. Journal of Guidance, Control, and Dynamics (2007). doi: $10.2514 / 1.26311$ 